\title{
Applying multiparametric ultrasonic nondestructive test for structural characterization of age hardened aluminum alloy
}

\author{
Erick Cerqueira das Neves ${ }^{1}$ \\ Ivan Costa e Silva ${ }^{2}$ \\ Jorge Luis Braz Medeiros ${ }^{3}$ \\ Luciano Volcanoglo Biehl ${ }^{3}$ \\ Carlos Otávio Damas Martins ${ }^{1 *}$ (B)
}

\begin{abstract}
Structural integrity is a major concern for both manufacturers and consumers, thus health monitoring is mandatory for a proper quality control. The use of more reliable and widespread techniques is urged. In this context, this work developed a nondestructive procedure for microstructural characterization of age-hardened aluminum alloys. By the combination of ultrasonic inspection parameters, we developed two highly sensitive methods of hardness evaluation. The results proved the versatility of ultrasonic waves for materials inspection and characterization, expanding the onsite evaluations range.
\end{abstract}

Keywords: Structural integrity; Materials manufacturing; Quality control; Nondestructive tests; Multiparametric analysis; Ultrasonic waves.

\section{Introduction}

Nowadays, the focus on equipment best performance demands applying a more reliable combination of materials selection, manufacturing, and quality control. These are the basis of structural integrity and health monitoring (SHM) science. SHM relies on applying advanced engineering knowledge to sustain the safety and reliability of structural components [1-4].

In traditional manufacturing, four metallurgical characteristics control all the material properties: chemical composition, microstructure, crystal structure, and dislocation density. Manufacturers often apply metallography (which involves cutting, polishing, grinding, and etching) for microstructural evaluation and destructive tests for mechanical properties analysis and determination. Despite providing a direct measurement, these tests destroy or change the part, preventing its further use. For these reasons, modern researchers and engineers are searching for the development and application of nondestructive tests (NDT) for materials characterization [3-9].

NDT are noninvasive techniques applied for a wide range of materials. The main advantage relies on its capability to analyze without compromise future use. However, NDT's application in support of SHM demands the use of reliable and cost-effective methods, combining data acquisition and interpretation $[1,6,9]$.

Ultrasonic is one of the more flexible NDT in the market. Changes in the materials' microstructural or mechanical properties influence the ultrasonic wave propagation through the elastic medium. This wave propagation provides a large amount of information, applied in SHM and quality control. The challenge is to find the proper configuration to guarantee a reliable NDT [6-10].

Recent publications relate ultrasonic inspection to materials characterization. Tariq et al. [11] correlated the hardness and microstructure of 2XXX aluminum alloys with ultrasonic and eddy current results. The authors showed that the sound velocity (measured by $2 \mathrm{MHz}$ and $4 \mathrm{MHz}$ transducers) increases non-monotonically in the same way as hardness increases. Rajendran et al. [12] applied the ultrasonic technique for heat treatment evaluation of A8090 aluminum alloys. They found a good correlation for the ultrasonic pulse velocity, precipitation, and dissolution of secondary phases. Other authors applied the ultrasonic technique to evaluate elastic modulus, grain size, and yield strength of steel and titanium alloys. The results proved the potentials of NDT to quality control of materials manufacturing [13-20].

${ }^{1}$ Programa de Pós-graduação em Ciência e Engenharia de Materiais - P2CEM, Universidade Federal de Sergipe - UFS, São Cristóvão, SE, Brasil. ${ }^{2}$ Programa de Pós-graduação em Engenharia de Materiais - PPGEM, Instituto Federal de Educação, Ciência e Tecnologia da Bahia - IFBA, Salvador, BA, Brasil.

${ }^{3}$ Programa de Pós-graduação em Engenharia Mecânica - PPMec, Universidade Federal de Rio Grande - FURG, Rio Grande, RS, Brasil

*Corresponding author: cmartins@academico.ufs.br 


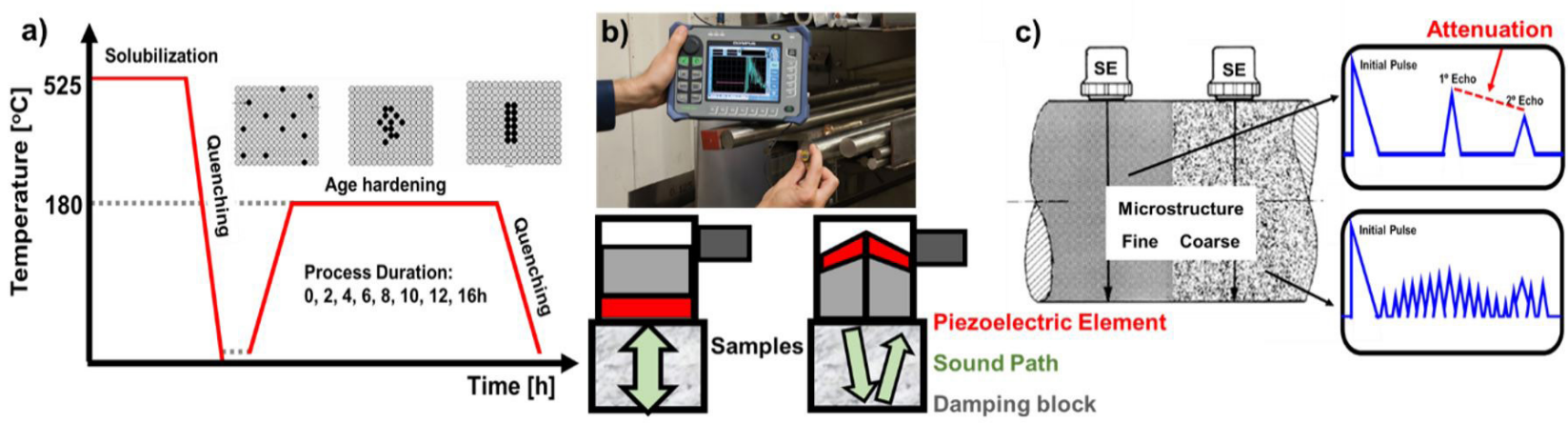

Figure 1. Schematic representation of the T6 heat treatment cycle for the A6351 aluminum alloy (a) and the ultrasonic inspection variation (b) with microstructure evaluation (c) [adapted from $[8,9,24]$.

To investigate the reliability of ultrasonic NDT for materials characterization, this research focuses on the evaluation of A6351 aluminum alloy - T6. A6351 is a precipitation-hardened alloy of the $\mathrm{Al}-\mathrm{Si}-\mathrm{Mg}$ system, containing about $2.5 \%$ (in mass) of solute. In the artificially aged condition (T6), the alloy has moderate mechanical strength (yield limit near $285 \mathrm{MPa}$ ), influenced by the formation of non-equilibrium precipitates $\left(\mathrm{Mg}_{2} \mathrm{Si}\right)$. Due to its attractive combination of mechanical, process, and corrosion properties, this aluminum alloy finds several applications in the automotive, construction, aerospace, and offshore industries [21-24].

By varying the type of transducer (single or dual element) and combining further statistical analyses, we developed a multiparametric ultrasound inspection for microstructural evaluation with high correlation $\left(\mathrm{R}^{2}>90 \%\right)$. Among its main advantages, this technique is fast, low-cost, noninvasive whilst being sensitive, thus appropriate for manufacturing quality control.

\section{Materials and methods}

A6351 Aluminum alloys $(94.430 \mathrm{Al}, 0.586 \mathrm{Mg}$, $1.120 \mathrm{Si}$, \% weight) were analyzed in this work.

Following the methodology of Nandy et al. [24], 27 cylindrical samples (20 millimeters thickness and diameter) were heat-treated (in an FL - 1300 oven from INTI) by the combination of solubilization, and quenching processes, followed by artificial age hardening (T6 ${ }^{1}$ ), in an SL 102/480 oven from Solab), as shown in Figure 1a. Briefly, nine groups of samples were heated up to $525^{\circ} \mathrm{C}$ and ice quenched, followed by age hardening at $180^{\circ} \mathrm{C}$ from 0 to 16 hours $(0,2,4,6,8,10,12,14,16$ hours $)$.

\footnotetext{
1 T6 designation applies to products that undergo no cold working after solubilization, or in which the effects of cold working associated with flattening or straightening do not alter the limits of mechanical properties [21].
}

To analyze the microstructure of the samples by scanning electron microscopy (Jeol model JSM-5700 SEM), the samples were ground, polished and chemically attacked with Weck solution.

Hardness measurements were conducted using a Vickers hardness equipment (Hoyton model VS700) with a $2 \mathrm{~kg}$ load, and 10 seconds of indentation.

The ultrasonic analysis was executed, by the pulseecho method, using a SIUI - CTS 30A ultrasonic thickness measurement, with dual-element transducers (providing one ultrasonic information: sound velocity, SV) and in a Sonotron - Isonic 2005, with single-element transducer (providing two ultrasonic information: SV and sound attenuation, SA). By the variation of the transducers type (single-element, SE, and double-element, DE) and frequencies $(2,2.25,4,5$, and $7.5 \mathrm{MHz}$ ), the ultrasonic data were analyzed and correlated with hardness and age hardening duration.

The frequency variation provides sound waves with different wavelength, which influence the sound propagation and interaction with the bulk material [14].

Therefore, by varying the type of transducer (SE or $\mathrm{DE})$ and ultrasound frequencies $(2,2.25,4,5$, and $7.5 \mathrm{MHz})$, we analyzed and correlated the ultrasonic data with materials' hardness and processing (age hardening duration). As illustrated in Figure 1b, SE or DE ultrasonic transducers can be used to measure SV. The main consequence of the transducer type variation relates to the near field configuration of the wavefront. Due to the damping blocks' presence, the DE transducers have a smaller near field length, thus the best choice for thickness measurement. However, in addition to ultrasonic equipment adjustment, the transducer selection is a compromise between sound path, wave interaction, and materials configuration. Attenuation refers to the loss of acoustic energy as the ultrasonic beam passes through the material. The coarse microstructure tends to disperse and attenuate the acoustic energy through the sound path (Figure 1c). The amplitude variation between two echoes in the A-scan represents the attenuation (requires advanced ultrasonic equipment) [6-10]. 
This research analyzed the hypothesis of "ultrasonic multiparametric analysis provides reliable results for the microstructural evaluation of T6 aluminum alloys".

Therefore, we divided the experimental in two parts:

1) The evaluation of the influence of the age-hardening duration in the sound velocity (to select the best ultrasonic combination for step 2);

2) The development of a reliable NDT hardness measurement technique by the application of the ultrasonic method.

The results presented in this article represent the average value of the 100 data/group of samples (10 samples/ process $\mathrm{x} 10$ points/sample). The standard deviation for ultrasonic and hardness measurements was lower than 5\%.

Statistical analysis (linear regression and variability) was applied for both technique selection (type of transducer) and evaluation of hardness measurements. By definition, linear regression identifies the equation that produces the smallest difference between all the observed values and their fitted values [25].

\section{Results}

Figure 2 presents the results obtained by the Vickers hardness and SEM evaluation. Like Nandy et al. [24], the maximum hardness value was achieved after 8 hours of age hardening (Figure 2a). The statistical analysis (Figure 2b) indicates the best results for $2.25 \mathrm{MHz}$ (SE) transducer. SEM analysis (Figure $2 \mathrm{c}$ to f) showed that the age hardening increasing provides the formation and growth of the $\mathrm{Mg}_{2} \mathrm{Si}$ precipitates (black dots) in the aluminum matrix. Despite the representativeness and direct results, destructive methods are invasive, timeconsuming, and difficult to apply onsite.

Figure 3 illustrates the ultrasonic results for the evaluation of the A6351 samples.

The combination of low frequency and a single element transducer (2.25 MHz SE) provided the highest variability (Figure 3a). This relates to the depth of penetration, combined with the perpendicular wave path originated by the ultrasonic transducer. Despite reducing the near field length, the DE transducer sound path inclination promotes wave dispersion and loss of correlation (Figure 1).

Figure $3 \mathrm{~b}$ shows the sound attenuation variation with the age-hardening duration obtained with the $2.25 \mathrm{MHz}$ and the $4 \mathrm{MHz}$ SE transducers, providing a multiparametric linear regression.

Figure 4 presents the Vickers hardness comparison between conventional and NDT methods (Equations 1-4). The NDT single and dual parameters correlation presented remarkable similarity with the direct destructive measurements.

Table 1 compares the statistical parameters obtained by the correlation analysis of sound parameters
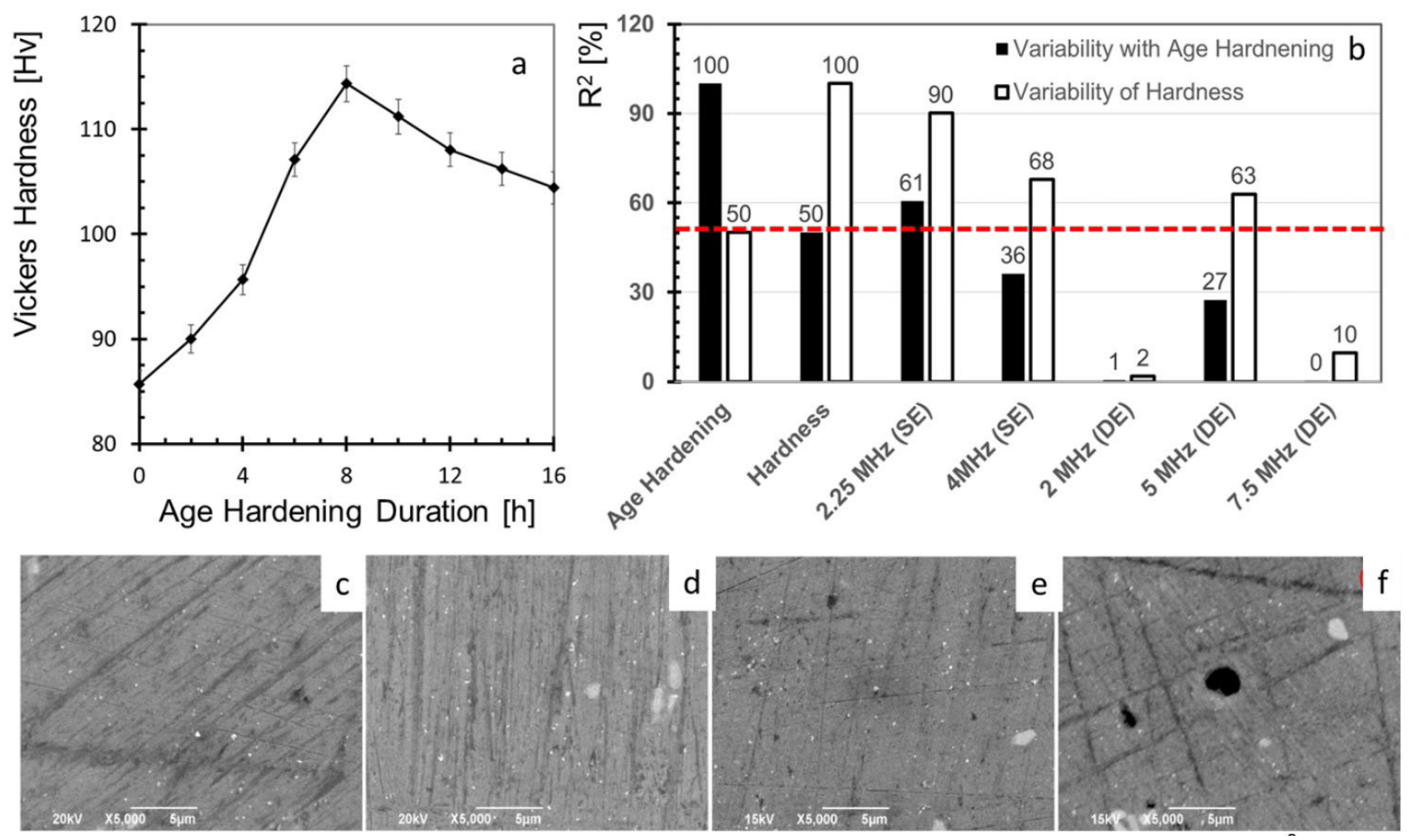

Figure 2. Data evaluation for T6 A6351 alloy: Hardness (a), Coefficient of determination, $\mathrm{R}^{2}$ (b) and microstructural variation with artificial

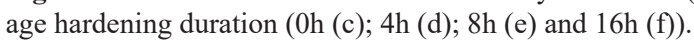



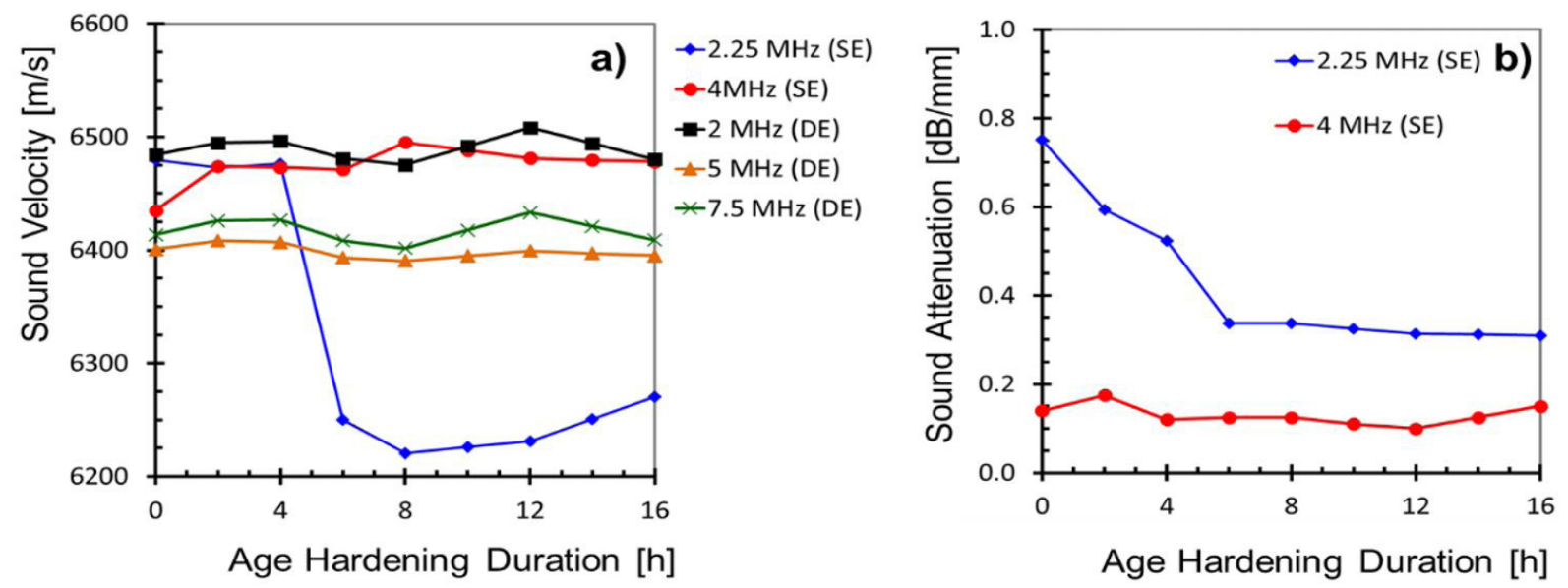

Figure 3. Ultrasonic data variation with artificial age hardening duration.
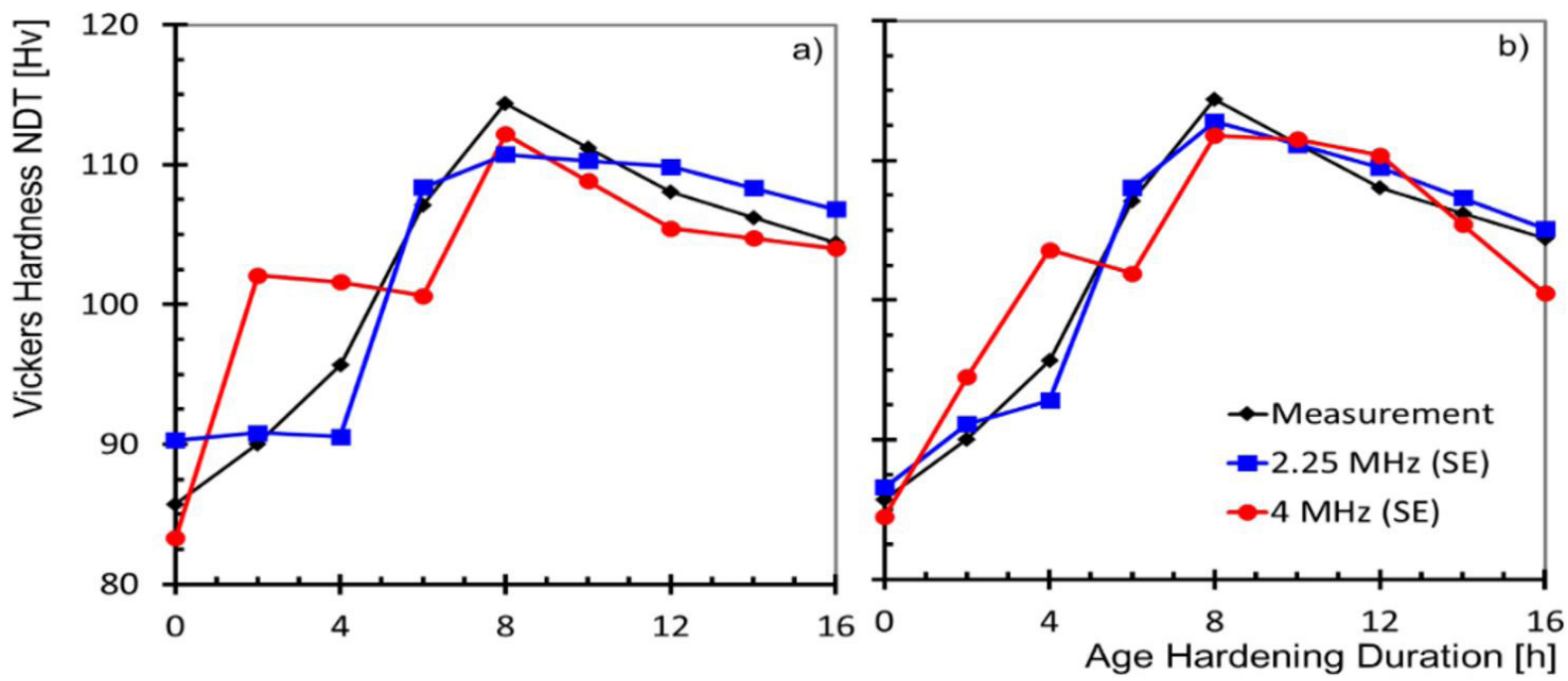

Figure 4. Hardness variations analyzed by destructive and non-destructive tests.

Table 1. Statistical evaluation for the linear regression analysis of ultrasonic and hardness data

\begin{tabular}{|c|c|c|c|c|c|}
\hline \multirow{2}{*}{ US } & \multirow{2}{*}{$\begin{array}{l}\text { Transducer frequency } \\
\text { Ultrasonic parameter }\end{array}$} & \multicolumn{2}{|c|}{$2.25 \mathrm{MHz}(\mathrm{SE})$} & \multicolumn{2}{|c|}{$4 \mathrm{MHz}(\mathrm{SE})$} \\
\hline & & $S V$ & $S V, S A$ & $S V$ & $S V, S A$ \\
\hline \multirow{6}{*}{ 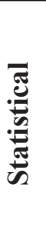 } & $\mathrm{R}^{2}[\%]$ & 90,16 & 92,40 & 67,80 & 81,89 \\
\hline & $\mathrm{R}_{\text {adjusted }}^{2}[\%]$ & 88,76 & 90,34 & 63,20 & 75,86 \\
\hline & Standard Error & 3,29 & 2,92 & 5,95 & 4,82 \\
\hline & Observations & 90 & $=90$ & 90 & 90 \\
\hline & $\mathrm{F}_{\text {calculated }}$ & 64,15 & 66,45 & 14,74 & 13,57 \\
\hline & $\mathrm{F}_{\text {signification }}$ & 0,00 & 0,00 & 0,01 & 0,01 \\
\hline
\end{tabular}

and hardness measurements. Both $\mathrm{R}^{2}$ and adjusted $\mathrm{R}^{2}$ were selected for the statistical evaluation. Whilst $\mathrm{R}^{2}$ evaluates the scatter of the data points around the fitted regression line, the adjusted $\mathrm{R}^{2}$ is applied for multiple linear regression. Its parameter, like $\mathrm{R}^{2}$, with corrections, relates to the inclusion of extra variables in the statistical model. The larger the $\mathrm{R}^{2}$ values, the better the regression model fits the observations [25].
$2.25 \mathrm{MHz}(\mathrm{SE}) ; H_{S V}=599.63-0.08 * \mathrm{SV}\left(\mathrm{R}_{\mathrm{Adj}}^{2}=88.76 \%\right)$

$2.25 \mathrm{MHz}(\mathrm{SE}) ; H_{S V ; S 4}=422.66-0,05 * S V-23.53^{*}{ }^{*}\left(\mathrm{R}_{\mathrm{Adj}}^{2}=90.34 \%\right)$

$4 \mathrm{MHz}(\mathrm{SE}) ; H_{S V}=0.48 * S V-3014.05\left(\mathrm{R}_{\mathrm{Adj}}^{2}=63.20 \%\right)$

$4 \mathrm{MHz}(\mathrm{SE}) ; H_{S Y ; S 4}=0.41^{*} S V-172.84 * S A-2541.24\left(\mathrm{R}_{\mathrm{Adj}}^{2}=75.86 \%\right)$ 


\section{Discussion}

Modern engineering demands the optimization of process manufacturing, operation, and quality control. In this sense, both sellers and buyers share the responsibility for component performance and integrity [1-4].

Manufacturers often try to reduce costs by modifying process parameters like heat treatment time, speed, temperature, and medium. For this reason, the microstructural and mechanical evaluation must be applied (sometimes onsite), this configures a significant opportunity for NDT $[1,4]$.

In this research, we search for an ultrasonic nondestructive procedure to characterize A6351 T6 heattreated aluminum alloys.

Since the 6xxx aluminum alloys' mechanical properties result from the formation of the intermetallic $\mathrm{Mg}_{2} \mathrm{Si}$ by heat treatment, the engineering community is concerned about their manufacturing and quality control [21-24].

The A6351 aluminum alloy had a hardness complex distribution, influenced by the age-hardening duration. In the first step, the heating above $520^{\circ} \mathrm{C}$ promotes the magnesium $(\mathrm{Mg})$ and silicon $(\mathrm{Si})$ dissolution in the aluminum (Al) matrix. After the abrupt cooling, the reheating above $180^{\circ} \mathrm{C}$ (artificial age hardening) promotes different types of $\mathrm{Mg}-\mathrm{Si}$ precipitates [24].

The time consuming during heat treatment leads to more stable and coherent precipitates, which increase the hardness and strength of the material. After a certain period, as the precipitates size increase, they become incoherent with the matrix, decreasing the mechanical performance. This article presented similar results (Achieving the maximum hardness after 8 hours of age hardening).

The challenge faced relates to developing the best ultrasonic configuration, related to equipment and transducers selection, to increase the technique sensitivity to microstructural variations, provided by the age hardening process (T6).). During the propagation through the bulk material, ultrasonic waves interact with materials interfaces (discontinuities, grain boundaries, precipitates, and secondary phases). These interactions influenced the wave velocity and attenuation, providing a correlation between materials ultrasonic and microstructural properties [14-20].

The results demonstrated a good correlation between ultrasonic and mechanical properties data (for statistical analysis, an $\mathrm{R}^{2}$ above $75 \%$ is considered good, indicating that $75 \%$ of the data fits the linear model).

The system with the $2.25 \mathrm{MHz}$ SE transducer provides the best results $\left(\mathrm{R}^{2}>90 \%\right)$. This configuration provides the best interaction between ultrasonic and microstructural properties.

We verified the influence of wave frequency on the final NDT hardness results. We showed that by increasing frequency, there is a decrease on the wave penetration, and on the sensibility to microstructural variation. In addition, the application of a DE transducer reduces the technique's sensitivity.

Figure 4 indicates that the application of a two parameters procedure increased the final correlation by
$3.5 \%$ ( $\mathrm{R}^{2}$ increased from 90.16 to $\left.92.4 \%\right)$. In agreement to Tariq et al. [11], aluminum microstructure variation influenced the ultrasonic data sensitivity (sound velocity and attenuation). Using three 2XXX Al-alloy, the authors applied the pulse-echo ultrasonic method with $2 \mathrm{MHz}$ and 4 $\mathrm{MHz}$ transducers. The high-frequency transducer provided the best results. Despite the good correlations between hardness and ultrasonic data (97\% SV and $87 \%$ SA), the authors did not apply a multiparametric analysis.

Rajendran et al. [12] applied the ultrasonic technique for the microstructural evaluation of a heat-treated Al-Li 8090 alloy. Their investigation was conducted through transmission ultrasonic method, which requires a huge apparatus with a pair of $5 \mathrm{MHz}$ SE transducers. The authors showed good ultrasonic sensitivity for microstructural variation, but they did not proceed with a multiparametric analysis of ultrasonic data.

In this research, we advanced data analysis and interpretation of ultrasound technique to demonstrate the benefits of a multiparametric (and data fusion) analysis.

Despite the higher cost of initial investment in comparison to simple ultrasonic thickness measurement, this multiparametric evaluation approach enables an increase in sensitivity and versatility. The development and application of NDT microstructural characterization methods improves the quality control applicability, increasing the materials integrity assessment and performance control, this is the basis of structural integrity and health monitoring science [1].

\section{Conclusion}

This research evaluated the applicability of nondestructive ultrasonic waves for the characterization of heat-treated T6 A6351 aluminum alloys. The challenge faced relates to developing the best inspection configuration to increase its sensitivity to microstructural variations provided by the age-hardening process.

The combination of equipment configuration resulted in two reliable NDT procedures. We showed correlations of $\left(R^{2}\right) 90.16 \%$ and $92.4 \%$. The final selection depends on the compromise between cost, complexity, and sensitivity, once the two parameters regression demands the extraction and analysis of A-Scan data.

The development and application of NDT microstructural characterization methods will elevate the quality control applicability, increasing the materials integrity assessment and performance evaluation.

\section{Acknowledgements}

The authors dedicate the article to the memory of Prof. Telmo R. Strohaecker. 


\section{References}

1 Czichos H. Handbook of technical diagnostics. Germany: Springer; 2013.

2 Mevissen F, Meo M. A review of NDT/structural health monitoring techniques for hot gas components in gas turbine. Sensors (Basel). 2019;19(3):1-37.

3 Farag MM. Materials and process selection for engineering design. 3rd ed. USA: Ed. Taylor \& Francis; 2014.

4 Achenbach JD. Structural health monitoring - What's is the prescription? Mechanics Research Communications. 2009;36(2):137-142.

5 Mix PE. Introduction to nondestructive testing. 2th ed. USA: JWS; 2005.

6 Hellier CJ. Handbook of nondestructive evaluation. USA: McGill; 2003.

7 Muthumari S, Singh A. Review of various ultrasonic techniques employed in modern industries. International Journal of Engineering Science and Technology. 2011;3(4):3078-3085.

8 Brook MV. Ultrasonic inspection technology development and search unit design. USA: John Wiley \& Sons; 2012.

9 Nenekar PP, Shah BK. Characterization of material properties by ultrasonics. National Seminar \& Exhibition on Non-Destructive Evaluation, 2003;249:25-38.

10 Scruby CB. NDE research makes a difference. In: Tamburrino A, Melikhov Y, Udpa L, editors. Electromagnetic nondestructive evaluation XI. Amsterdam: IOS Press; 2008.

11 Tariq F, Naz N, Baloch RA, Faisal. Characterization of material properties of 2xxx series Al-alloys by nondestructive testing techniques. Journal of Nondestructive Evaluation. 2012;31(1):17-33.

12 Rajendran V, Muthu Kumaran S, Jayakumar T, Palanichamy P, Shankar P, Raj B. Microstructure and ultrasonic behavior on thermal heat-treated Al-Li 8090 alloy. Journal of Alloys and Compounds. 2009;478(1-2):147-153.

13 Majumdar P, Singh SB, Chakraborty M. Elastic modulus of biomedical titanium alloys by nanoindentation and ultrasonic techniques - A comparative study. Materials Science and Engineering A. 2008;489(1-2):419-425.

14 Ruiz A, Fuentes-Corona KJ, López VH, León CA. Microstructural and ultrasonic characterization of 2101 lean duplex stainless steel welded joints. Applied Acoustics. 2017;117:12-19.

15 Ruiz A, Ortiz N, Medina A, Kim J-Y, Jacobs LJ. Application of ultrasonic methods for early detection of thermal damage in 2205 duplex stainless steel. NDT \& E International. 2013;54:19-26.

16 Freitas VDA, Albuquerque VHC, Silva EM, Silva AA, Tavares JMRS. Nondestructive characterization of microstructures and determination of elastic properties in plain carbon steel using ultrasonic measurements. Materials Science and Engineering A. 2010;527(16-17):4431-4437.

17 Torello D, Selby N, Kim JY, Qu J, Jacobs LJ. Determination of absolute material nonlinearity with air-coupled ultrasonic receivers. Ultrasonics. 2017;81:107-117.

18 Carvajal L, Artigas A, Monsalve A, Arévalo E. Monitoring heat treatments in steels by a nondestructive ultrasonic method. Materials Research. 2016;20(suppl 2):347-352.

19 Aghaie-Khafri M, Honarvar F, Zanganeh S. Characterization of grain size and yield strength in AISI 301 stainless steel using ultrasonic attenuation measurements. Journal of Nondestructive Evaluation. 2012;31(3):191-196.

20 El Rayes MM, El-Danaf EA, Almajid AA. Materials Characterization and correlation of mechanical, microstructural and ultrasonic properties of power plant steel. Materials Characterization. 2015;100:120-134.

21 Kaufman JG. Introduction to aluminum alloys, and tempers. ASM International; Materials Park (OH), 2000,258 p.

22 Hosseinifar M, Malakhov DV. The sequence of intermetallic formation during the solidification of an Al-Mg-Si alloy containing la. Metallurgical and Materials Transactions. A, Physical Metallurgy and Materials Science. 2011;42(3):825-833.

23 Oliveira M, Biehl LV, Medeiros JLB, Avellaneda CAO, Martins COD, Souza J, et al. Manufacturing against corrosion: increasing materials performance by the combination of cold work and heat treatment for 6063 aluminum alloy. Materials Science (Medžiagotyra). 2020;26(1):30-33.

24 Nandy S, Bakkar MA, Das D. Influence of ageing on mechanical properties of 6063 al alloy. Mater. Today Proc. 2015;2(4):1234-1242.

25 Frost J. Regression analysis - An intuitive guide for Using and Interpreting Linear Models; Ed. Statistics by Jim Publishing, USA, 2019, 367 p.

Received: 18 Aug. 2020

Accepted: 23 Nov. 2020 